\title{
TITLE: IMPACT OF ROUTINE TRANEXAMIC ACID IN CARDIAC SURGERY: SINGLE CENTRE REVIEW
}

AUTHORS: Massimiliano Meineri MD, Marcin Wasowicz PhD MD, Keyvan Karkouti MD, George Djaiani MD, Ludwik Fedorko MD, Tirone David MD, Jacek Karski MD

AFFILIATION: Department of Anesthesia \& Pain Management and Division of Cardiac Surgery, Toronto General Hospital, University Health Network, University of Toronto, 200 Elizabeth Street, Toronto, ON, M5G 2C4

INTRODUCTION. Cardiopulmonary bypass (CPB) alters the hemostatic balance and predisposes cardiac surgery patients to an increased risk of excessive postoperative bleeding. Antifibrinolytics such as Tranexamic Acid (TA) have shown in multiple studies to reduce postoperative bleeding and blood transfusions requirements. To date no study has addressed the safety of prophylactic use of TA.

METHODS. In this report we present the major outcomes (mortality, stroke, renal failure, myocardial infarction, chest reopening for bleeding and infection) in 10,870 patients from a single centre who received TA before cardiac surgery. Following REB approval all patients who underwent heart surgery during 1999-2003 at our institution and received TA as a prophylactic measure to decrease blood loss were reviewed. Data from our prospectively collected database was analyzed for occurrence of major outcomes. Anesthetic management was uniform in all cases; all patients received TA before sternotomy (50-100 mg/kg.b.w.).

RESULTS. 7000 patients had CABG (64\%), 2233 single valve surgery (21\%) and 1637 (15\%) other cardiac surgery.

Major preoperative demographics are presented in the Table 1.

\begin{tabular}{|l|c|c|}
\hline \multicolumn{1}{|c|}{ Variable } & Mean value & SD \\
\hline Age & 62 & \pm 12 \\
\hline Weight & 79 & \pm 17 \\
\hline PT $(\mathrm{sec})$ & 1.09 & \pm 0.2 \\
\hline Hg level $(\mathrm{g} / \mathrm{dl})$ & 134 & \pm 16 \\
\hline Platelet count $\left(10^{3} / \mathrm{mm}^{3}\right)$ & 234 & \pm 70 \\
\hline Creatinine level $(\mathrm{mg} / \mathrm{dl})$ & 97 & \pm 62 \\
\hline
\end{tabular}

Major complications included mortality (202 pt.-1.86\%), stroke (158 pt.-1.45\%), renal failure (160pt.-1.47\%), MI (248 pt-2.28\%), re-op for bleeding (430 pt-3.4\%), sepsis or deep sternal infections (238 pt-2.19\%) and low cardiac output syndrome (478 pt-4.4\%). $58.8 \%$ received RBC transfusion, 19.5\% received FFP and 19.5\% received platelets. The average ICU and hospital length of stay was 1 and 7 days respectively.

DISCUSSION. It has been demonstrated in previous studies that routine use of TA in cardiac surgery decreases blood loss and transfusion requirements. Routine use of TA preoperatively in cardiac surgical patients did not affect adversely outcomes in our institution. Mortality, stroke and the incidence of MI in this patient population remains below the rates of complications as published in the society of Thoracic Surgery Database. 